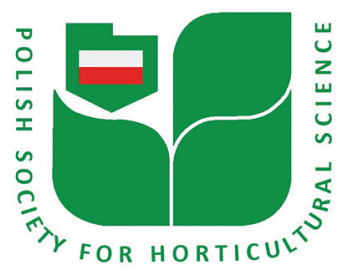

Folia Hort. 33(2) (2021): 376-389

\title{
Salicylic acid effect on the mechanism of Lelliottia amnigena causing potato soft rot
}

\author{
Richard Osei ${ }^{1}$, Chengde Yang ${ }^{1,2, *}$, Lingxiao Cui ${ }^{1}$, Lijuan Wei, \\ Mengjun Jin ${ }^{1}$, Solomon Boamah ${ }^{1}$ \\ ${ }^{1}$ College of Plant Protection, Gansu Agricultural University, Lanzhou, 730070, P.R. China \\ ${ }^{2}$ Biocontrol Engineering Laboratory of Crop Diseases and Pests of Gansu Province, Lanzhou, 730070, P.R. China
}

\begin{abstract}
Salicylic acid (SA) plays an important role in protecting plants from biotic stresses. Lelliottia amnigena is a newly identified potato soft rot pathogen and there are no adequate studies on this soft rot pathogen. Therefore, this paper focussed on the effect of SA on the mechanism under which L. amnigena causes potato soft rot. L. amnigena was examined and detected to secrete pectinase, proteases, pectin lyase and cellulase, which are the most important pathogenic enzymes involved in the production of plant diseases. Sterilised healthy potato tubers were inoculated with $0.2 \mathrm{~mL}$ of L. amnigena suspension (3.69 $\left.\mathrm{CFU} \cdot \mathrm{mL}^{-1} \times 10^{7} \mathrm{CFU} \cdot \mathrm{mL}^{-1}\right)$. After $24 \mathrm{~h}, 200 \mu \mathrm{L}$ of four different SA concentrations $(0.5 \mathrm{mM}, 1.0 \mathrm{mM}, 1.5 \mathrm{mM}$ and $2.0 \mathrm{mM}$ ) were used to treat the tubers. Co-culture of L. amnigena and SA significantly reduced the activity of pectinase, protease, pectin lyase and cellulase by an average of $33.8 \%, 43.4 \%, 67.7 \%$ and $46.9 \%$, across the four concentrations $(0.5 \mathrm{mM}, 1.0 \mathrm{mM}, 1.5 \mathrm{mM}$ and $2.0 \mathrm{mM})$, respectively, compared to the control. The average disease index was reduced by $54.7 \%$ across the four SA concentrations. Treatment with SA induced transcriptional levels of the superoxide dismutase, peroxide, catalase and glutathione S-transferase across the four levels by an average of 3.87, 3.25, 3.97 and 3.94-fold, respectively, compared to control. Based on our results, we could state that SA could reduce the activities of these extracellular enzymes produced by L. amnigena by modulating both enzymatic and non-enzymatic antioxidant activities and gene expression that induce natural resistance in plants against bacterial infections.
\end{abstract}

KEYWORDS: antioxidant enzymes, disease, extracellular enzymes, pathogen, gene expression

\section{INTRODUCTION}

Potato (Solanum tuberosum) is the fourth most important food crop in the world after rice, wheat and maize according to Dutt et al. (2017) and Rahaman and Shehab (2019). It is used worldwide to produce various food substances such as chips, crisps, potato flour, vegetable salad, canned food and feed for livestock (Manzira, 2010). China is the leading potato producer in the world, accounting for $26.3 \%$ of global potato production, followed by Russia and India (Wang et al., 2018). However, the production and quality of potato tubers are affected by many different biotic and abiotic stresses including soft rot-causing pathogens (Pectobacterium and Dickeya) and other diseases such as blackleg, scab and late blight. Mostly, soft rot occurs during production in the field and storage (Pérombelon, 2002; Czajkowski et al., 2011). The virulence and pathogenicity of these bacteria are due to their ability in secreting large amounts of extracellular plant cell wall-degrading enzymes (PCWDE), including pectin lyases, proteases, pectinase and cellulases, leading to extensive tissue maceration,

*Corresponding author.

e-mail: yangcd@gsau.edu.cn (Chengde Yang). 
rot and subsequent death of the entire plant (Barras et al., 1994; Toth et al., 2003). They cause extensive tissue damage, invasiveness, dissemination, colonisation, and can promote the destruction of the plant cell wall. In addition, they break down plant substances into smaller molecules that are absorbed easily and utilised by pathogen for their growth and energy. The symptoms of soft rot are caused by the cumulative action of pectinases (especially pectate lyases) which destroy pectin, the adhesive material of the plant cell wall.

Many physical methods such as the production of certified seed, rigorous inspections, seed testing systems, good sanitation during harvest, sorting and grading of tubers, and the requirement for farmers to use varietal resistance seed have been used to control potato soft rot, but these procedures are expensive, time-consuming and do not eliminate pathways or avenues through which pathogenicity becomes established (MauchMani et al., 2017; Silva et al., 2018). Chemical methods are also used to control bacterial pathogens. Synthetic bactericides are not the preferred method for controlling plant pathogens due to their negative effects on humans and the environment and the possibility of the selection of multidrug-resistant bacterial strains (Abd El-Kahir, 2004; Jess et al., 2014). As a promising alternative to the use of synthetic bactericides, phytohormones such as salicylic acid (SA) that induces natural resistance in plants against bacterial infections can be considered (Koo et al., 2020). They serve as chemical mediators to control cellular activities in higher plants (Kazan, 2015; Aymen, 2018).

Salicylic acid is one of the phenolic compounds formed by plants with a hydroxyl or derivative group (Yousif, 2018). Plant phenols are commonly referred to as specialised metabolites involved in important functions such as biosynthesis of lignin and allelopathic compounds that control plant responses to living stimuli (Kubalt, 2016), thermoregulation (Klessig et al. 2018) and defence signalling activity in plants (Kubalt, 2016). It also stimulates morphological, physiological and biochemical pathways of general plant' defence (Wang and Li, 2006; Vlot et al., 2009). In inducing disease tolerance in plants, SA also controls ion uptake and antioxidant defence (Jayakannan et al., 2015). Due to its contribution to plant protection response under biotic and abiotic stresses, SA has received much attention.

Lelliottia amnigena, which is a Gram-negative, plant-pathogenic bacterium belonging to the family Enterobacteriaceae is a new species identified as a causal agent of soft rot of potato (Abd-Elhafeez et al., 2018). Many crops, including apple, carrot, lettuce, onion, radish, strawberry and sugar beet, have been reported to be affected by $L$. amnigena, resulting in economic losses in agricultural production (AlKharousi et al. 2016; Hungund et al. 2010; Liu et al. 2016). Soft rot bacteria of the Lelliottia species produce and secrete PCWDE that causes the rotting of potatoes in the field and storage. Because they can produce a wider range of enzymes/isoenzymes more quickly and in higher quantities than pectolytic saprophytic bacteria, they can penetrate living plants more easily and induce infection (Bateman 2012; Collmer et al. 2012). In contrast to viruses specialised to infect a confined host range, the mechanisms that have evolved in the soft rot L. amnigena appear to allow a significant degree of plasticity in their metabolism. However, there is no adequate information on the SA effect on the mechanism of L. amnigena causing potato soft rot. Therefore, this study focussed on the SA effect on the L. amnigena mechanism of causing potato soft rot.

\section{MATERIALS AND METHODS}

The pathogen, strain PC3 (L. amnigena) with GenBank accession number of the 16S rRNA SUB10508072 PC3 OK447935 was obtained from the Plant Pathology Laboratory of Gansu Agricultural University, Lanzhou, P.R. China. L. amnigena was previously identified to cause potato soft rot in Egypt by Abd-Elhafeez et al. (2018) and onion decay in China by Liu et al. (2016). Strain PC3 was grown on nutrient agar (NA) at $37{ }^{\circ} \mathrm{C}$ for overnight. Bacteria suspension was prepared to a final concentration of 3.6 $\mathrm{CFU} \cdot \mathrm{mL}^{-1} \times 10^{7} \mathrm{CFU} \cdot \mathrm{mL}^{-1}$ using a serial dilution method described by Ben-David and Davidson (2014). SA (SA; 2-hydroxybenzoic acid), obtained from Sangon Biotech Co. Ltd, Shanghai, China, was used for the study. A $5 \times 2$ factorial experiment in a randomised complete block design with three replications was used both in the laboratory and greenhouse. Physiological and molecular parameters were determined after plant treatments.

\section{Potato tubers treatment}

Potato tubers (Solanum tuberosum L., Atlantic variety) were obtained from the local market, Lanzhou, P.R. China. Atlantic variety was selected due to its susceptibility to various rot infections and also a popular mid-season chipping potato cultivar in China. Matured healthy tubers of similar size with no visible physical injuries or infection were used. The tubers were surface sterilised by immersion in $0.5 \%$ sodium hypochlorite $(\mathrm{NaOCl})$ solution for $15 \mathrm{~min}$, washed with sufficient sterile water and then air-dried overnight. The sterilised tubers were cut in halves, washed by rinsing in sterile water for $3 \mathrm{~min}$, followed by surface sterilisation with $75 \%$ ethanol for $1 \mathrm{~min}$ and air drying. The treatments were: five levels of SA concentrations $(0.0 \mathrm{mM}, 0.5 \mathrm{mM}$, $1.0 \mathrm{mM}, 1.5 \mathrm{mM}$ and $2.0 \mathrm{mM}$ ) and two modalities of L. amnigena inoculation (L. amnigena inoculation and no L. amnigena inoculation). The treatment combinations were presented in Table 1. A total of 18 pots ( 6 treatments with 3 replicates) were used for each experiment. The negative control (plants growing in loamy soil under control conditions without L amnigena inoculation and SA treatment) whereas positive control (plants growing in loamy soil under conditions with $L$. amnigena inoculation). 
Table 1. Treatment combinations.

\begin{tabular}{lll}
\hline Group & Name & Treatment \\
\hline T1 & Negative control & Distilled water \\
T2 & Positive control & Strain PC3 $($ L. amnigena $)$ \\
T3 & PC3 $+0.5 \mathrm{mM} \mathrm{SA}$ & $\begin{array}{l}\text { Inoculation of strain } \\
\text { PC3 }+0.5 \mathrm{mM} \mathrm{SA}\end{array}$ \\
T4 & PC3 $+1.0 \mathrm{Mm} \mathrm{SA}$ & $\begin{array}{l}\text { Inoculation of strain } \\
\text { PC3 }+1.0 \mathrm{mM} \mathrm{SA}\end{array}$ \\
T5 & PC3 $+1.5 \mathrm{Mm} \mathrm{SA}$ & $\begin{array}{l}\text { Inoculation of strain } \\
\text { PC3 }+1.5 \mathrm{mM} \mathrm{SA}\end{array}$ \\
& & $\begin{array}{l}\text { Inoculation of strain } \\
\text { PC3 }+2.0 \mathrm{mM} \mathrm{SA}\end{array}$ \\
\hline
\end{tabular}

SA, salicylic acid.

\section{Preparation of $S A$ solution}

Salicylic acid - 2-hydroxybenzoic acid obtained from Sangon Biotech Co. Ltd., Shanghai, China, was used for the study. SA solutions at different concentrations (0 mM, 0.5 mM, 1. $0 \mathrm{mM}, 1.5 \mathrm{mM}$ and $2.0 \mathrm{mM}$ ) with $\mathrm{pH}$ at $6.0-6.5$ were prepared with distilled water containing $0.01 \%$ Tween-20 as surfactant according to the method of Cao et al. (2013) with modification. These ranges of concentrations were chosen because low or high SA levels were strictly correlated to a lower and higher oxidative stress according to Mateo et al. (2006).

\section{Impact of $S A$ on in vitro extracellular enzyme production of L. amnigena}

$0.2 \mathrm{~mL}$ of L. amnigena (strain $\mathrm{PC} 3$ ) (3.6 CFU $\cdot \mathrm{mL}^{-1} \times 10^{7} \mathrm{CFU} \cdot \mathrm{mL}^{-1}$ ) was inoculated into $10 \mathrm{~mL}$ of NA and allowed to grow at $37{ }^{\circ} \mathrm{C}$ for $12 \mathrm{~h}$ (overnight). Overnight cultures of the strain were re-suspended to the final concentration of 3.6 $\mathrm{CFU} \cdot \mathrm{mL}^{-1} \times 10^{7} \mathrm{CFU} \cdot \mathrm{mL}^{-1}$ in bacterial liquid with or without SA. Different concentrations $(0.5 \mathrm{mM}$, $1.0 \mathrm{mM}, 1.5 \mathrm{mM}$ and $2.0 \mathrm{mM}$ ) of SA were used. Culture supernatants from the growths at $37{ }^{\circ} \mathrm{C}$ were collected and analysed for the activity of protease $\left(\mathrm{U} \cdot \mathrm{mL}^{-1}\right)$, pectinase $\left(\mathrm{U} \cdot \mathrm{mL}^{-1}\right)$, pectin lyase $\left(\mathrm{U} \cdot \mathrm{mL}^{-1}\right)$ and cellulase (U/104 cell) according to the manufacturer's protocol/kit (Solarbio Science and Technology Company Ltd., Beijing, China). The activity of pectinase, protease, pectin lyase and cellulase were determined in a dual-wavelength spectrophotometer at the absorbance of $540 \mathrm{~nm}, 450 \mathrm{~nm}$ and $235 \mathrm{~nm}$, respectively. The experiment was repeated three times.

\section{Impact of SA on bacterial soft rot of potato tuber}

This experiment checked the effect of treating potato tubers with SA on the severity of soft rot disease. The experiment was conducted in the laboratory. Matured healthy potato tubers were surface sterilised with $75 \%$ ethanol for $1 \mathrm{~min}$ and then rinsed 3 times in sterile distilled water. The tubers were allowed to dry at room temperature. Ten tubers were used for each replicate. A total of 30 tubers were used for each treatment. A hole $(0.5 \mathrm{~cm}$ in diameter and $1 \mathrm{~cm}$ deep) was created in the centre of each sterilised tuber using a sterile cork borer (BML505-15 mm, Wuhan Servicebio Technology Co. Ltd., China). A solution of bacterial suspension (3.69 $\mathrm{CFU} \cdot \mathrm{mL}^{-1} \times 10^{7} \mathrm{CFU} \cdot \mathrm{mL}^{-1}$ at $0.2 \mathrm{~mL}$ ) was put in the hole of the tubers. After $24 \mathrm{~h}$, tubers were treated with SA at different concentrations ( $0 \mathrm{mM}, 0.5 \mathrm{mM}, 1.0 \mathrm{mM}$, $1.5 \mathrm{mM}$ and $2.0 \mathrm{mM}$ at $200 \mu \mathrm{L}$ ) through spraying with sterile distilled water as a negative control. Treated tubers were packed in clean, sterilised plastic containers, each lined with sterilised damp cotton and stored at room temperature for 14 days. Three replicates were used for each treatment. The experiment was repeated three times.

\section{Inoculation of tubers and disease assessment}

Inoculation of $0.2 \mathrm{~mL}$ of $L$. amnigena suspension was performed in the laboratory $24 \mathrm{~h}$ before treatment with SA as previously described. Disease index (DI) was recorded 7 days and 14 days after inoculation (DAI). The DI was scored by visually assessing the maceration area of each tuber using a visual scale of $0-4$, (Scherf et al., 2010) where $0=$ no rot, 1 indicated that $1-25 \%$ of the tubers were rotted, 2 indicated that $26-50 \%$ of the tubers were rotted, 3 indicated that $51-75 \%$ of the tubers were rotted and 4 indicated that $76-100 \%$ of the tubers were rotted. The DI was calculated as:

DI $(\%)=(S[$ number of diseased tubers in this index $\times \mathrm{di}] /$ [total number of tubers investigated $\times$ highest di] $) \times 100$

\section{The action of SA on the growth of potato plant}

Salicylic acid concentrations ( $0 \mathrm{mM}, 0.5 \mathrm{mM}, 1.0 \mathrm{mM}$, $1.5 \mathrm{mM}$ and $2.0 \mathrm{mM}$ ) were sprayed using Handheld Pressure Sprayer (301-B, Pinghu Kaixin Plastic Industry Co., Ltd., China) on the foliage of the plants $24 \mathrm{~h}$ after inoculation of the bacterial suspension (3.69 CFU $\cdot \mathrm{mL}^{-1} \times 10^{7} \mathrm{CFU} \cdot \mathrm{mL}^{-1}$ ) through stem injection $\left(0.2 \mathrm{~mL} \cdot\right.$ plant $\left.^{-1}\right)$. Briefly, this part of the experiment was conducted in a greenhouse (day temperature 25 $35{ }^{\circ} \mathrm{C}$, night temperature $18-22{ }^{\circ} \mathrm{C}$, daytime relative humidity $45-55 \%$ and light intensity $15,000-18,000 \mathrm{~lx}$ ). One tuber per pot was sown per plastic pots $(12.5 \mathrm{~cm}$ diameter, $9.5 \mathrm{~cm}$ deep) filled with $2 \mathrm{~kg}$ of loamy soil. SA treatments were repeated every 1 week and control plants were sprayed with distilled water. This procedure was repeated for 60 days. Treatments were arranged as randomised complete blocks with 30 potato plants. The experiment was repeated three times with three replications. After 60 days of treatment, plant height $(\mathrm{cm})$, the number of leaves per plant, leaf area $\left(\mathrm{cm}^{2}\right)$ and plant fresh weight $(\mathrm{g})$ traits were determined. The plant dry weight (g) was guided in an electric oven (YLD3000, Shanghai Yuejin Medical Equipment Co., Ltd., China) at $105^{\circ} \mathrm{C}$ until a constant weight was reached and then determined. Data were compared with plants under control conditions (plants without pathogen inoculation). The entire experiment was conducted three times under the same conditions with similar results and the data from the three experiments were pooled. 


\section{Measurement of chlorophyll and carotenoid content in leaves}

Total chlorophyll and carotenoids were extracted with 100\% acetone (10000418, Sinopharm Chemical Reagents Co. Ltd., China, $\geq 99.5 \%$ purity) according to the method of Lichtenthaler (1987). In brief, $0.2 \mathrm{~g}$ of fresh leaves was ground to powder in liquid nitrogen and homogenised with $5 \mathrm{~mL}$ of acetone and then centrifuged (BT16R, OLABO Scientific Co. Ltd, Jinan, China). The chlorophyll and carotenoid content were determined in a dual-wavelength spectrophotometer (EPOCH2 Plate Reader, BioTek, USA) at the absorbance of A661.6 nm at $644.8 \mathrm{~nm}$ and $470 \mathrm{~nm}$.

\section{Determination of malondialdehyde (MDA) and hydrogen peroxide $\left(\mathrm{H}_{2} \mathrm{O}_{2}\right)$ in leaves}

The content of MDA, a product of lipid peroxidation produced by the thiobarbituric acid reaction and an indicator of oxidative damage to a biological system, was measured according to the manufacturer's protocol/kit (BC0025, Solarbio Science and Technology Company Ltd., Beijing, China). The absorbance of each sample was measured at $600 \mathrm{~nm}, 532 \mathrm{~nm}$ and $450 \mathrm{~nm}$, respectively. The content of MDA was expressed as $\mu \mathrm{mol} \cdot \mathrm{g}^{-1}$ fresh weight $\left(\mu \mathrm{mol} \cdot \mathrm{g}^{-1} \mathrm{FW}\right)$. The content of hydrogen peroxide $\left(\mathrm{H}_{2} \mathrm{O}_{2}\right)$ in potato leaves was determined according to the manufacturer's protocol/kit (BC3595, Solarbio Science and Technology Company Ltd., Beijing, China). In brief, $0.1 \mathrm{~g}$ of fresh potato leaf was crushed in liquid nitrogen (Henan Boss Liquid Nitrogen Container Co., Ltd., China, $78.03 \%$ by volume, $75.5 \%$ by weight) and placed on an ice bath in $1 \mathrm{~mL}$ of acetone. The absorbance of each sample was measured at $415 \mathrm{~nm}$ using a spectrophotometer (EPOCH2 Plate Reader, BioTek, USA).

\section{Antioxidants enzymatic activities in potato leaves}

The total activities superoxide dismutase (SOD) (EC 1.15.1.1), catalase(CAT) (EC 1.11.1.6), peroxide(POD)(EC 1.11.1.7) and polyphenol oxidase (PPO) (E.C. 1.14.18.1) were determined according to the manufacturer's protocol. One unit of SOD (YX-W-A500-WST-8) activity was measured as the amount of crude enzyme extract that inhibited the reduction of $\beta$-nitroblue tetrazolium chloride by $50 \%$ at $560 \mathrm{~nm}$ in the spectrophotometer (EPOCH2 Plate Reader, BioTek, United States). CAT (YX-W-A501) activity was monitored in the spectrophotometer by calculating the degradation of $\mathrm{H}_{2} \mathrm{O}_{2}$ at $240 \mathrm{~nm}$. POD (YX-W-A502) activity, expressed as $\mathrm{U} \cdot \mathrm{mg}^{-1} \mathrm{FW}$, was determined spectrophotometrically by measuring the increased absorbance at $470 \mathrm{~nm}$. One unit of PPO was defined as the change in absorbance by $0.1 \mathrm{U} \cdot \mathrm{min}^{-1}$ under assay conditions. The antioxidant kits were provided by Solarbio Science and Technology Company Ltd., Beijing, China.

\section{Extraction of total RNA and analysis of gene expression}

Total RNA extraction and analysis of $100 \mathrm{mg}$ fresh potato leaves sprayed with different concentrations of SA were performed according to the methods of Xie et al. (2013) and using PureLink ${ }^{\circledR}$ RNA Mini Kit (Tiangen Biotechnology, Beijing, China). The quantity and quality of isolated RNA were analysed using a Nano-Drop spectrophotometer (Thermo Scientific, USA) at the absorbance of $230 \mathrm{~nm}$ and $260 \mathrm{~nm}$. The A260/A280 ratio indicated that the RNA was free from protein contamination. First-strand cDNA synthesis was performed using Revert Aid TM First Strand cDNA Synthesis Kit (Tiangen Biotechnology, Beijing, China). Specific primers for the SOD, POD, CAT, and glutathione S-transferase (GST) genes and the internal control actin gene were used to amplify amplicons specific for potato leaves as presented in Table 2. For quantitative real-time PCR (qRT-PCR), $2 \times$ SYBR Green qPCR Master Mix was used. Analysis $20 \mu \mathrm{L}$ reaction mixture consisting of $10 \mu \mathrm{L} 2 \times$ SYBR Green qPCR Master Mix, deionised water $(6.6 \mu \mathrm{L})$, diluted cDNA $(1 \mu \mathrm{L})$, ROX reference dye $(0.4 \mu \mathrm{L})$ and $1 \mu \mathrm{L}$ of each primer. The relative expression of (SOD, POD, CAT, GST and actin) genes was determined using the $2^{-\Delta \Delta C t}$ formula of Livak and Schmittgen (2001). Three biological repeats were performed for each experiment.

\section{Statistical analysis}

The data were tested in each experiment included SA controlling L. amnigena and breaking the mechanism of infection. Data were analysed using two-way ANOVA in SPSS version 16.0 (SPSS Inc., Chicago, IL, USA), and mean comparisons were made using Duncan's new multiple range test and the significance was considered at $p<0.05$.

\section{RESULTS}

\section{The mechanism under which L. amnigena causes soft rot}

The mechanism under which L. amnigena causes soft rot was determined in an in vitro on L. amnigena. Our result shows that $L$. amnigena produced extracellular enzymes such as pectinase, protease, pectin lyase and cellulase that contribute to the development of potato soft rot (Table 3).

\section{The impact of SA on L. amnigena mechanism of infection}

Our results showed that SA had a significant $(p<0.05)$ impact on the production of pectinase, protease, pectin lyase and cellulase. The addition of SA across the four concentrations (0.5 mM, $1.0 \mathrm{mM}, 1.5 \mathrm{mM}$ and $2.0 \mathrm{mM})$ 
Table 2. Gene description and primers sequences used for the qRT-PCR.

\begin{tabular}{llll}
\hline Gene symbol & Description & Primer sequence $\left(5^{\prime}-3^{\prime}\right)$ & Experiment \\
\hline SOD & Manganese & F-GCTGGTGCTAGAGTAGCCTG & Antioxidant activity test \\
& superoxide dismutase & R-TCAAAGTTATCTGCCGTTCTCCA & \\
POD & Peroxidase & F-GTTGCCTTATCAGGTTTGTCTTT & Antioxidant activity test \\
& & R-CGGACGTGTTTGAATCAACTT & \\
CAT & F-TTTCAGGAGATGTGCAGCGT & Antioxidant activity test \\
& & R-ATGTATGAGGCTTTTATGCTGCT & \\
GST & Glutathione S-transferase & F-AGCTGGTGCCCATCAATCTC & Antioxidant activity test \\
& R-CCCTCTGAGACTCCTAATGATCC & \\
ACT & Actin-related protein & F-GCTCCTAGAGCTGTATTCCCAAGT & Antioxidant activity test \\
& Actin & R-CAGTCGAAACGTGGTATCTTGACT & \\
\hline CAT, catalase; GST, Glutathione S-transferase; POD, Peroxidase; qRT-PCR, quantitative real-time PCR; SOD, superoxide dismutase.
\end{tabular}

Table 3. Production of extracellular enzymes by suspensions $\left(3.6 \mathrm{CFU} \cdot \mathrm{mL}^{-1} \times 10^{7} \mathrm{CFU} \cdot \mathrm{mL}^{-1}\right)$ from L. amnigena.

\begin{tabular}{ll}
\hline Extracellular enzymes & Enzyme activity $\left(\mathrm{U} \cdot \mathrm{mL}^{-1}\right)$ \\
\hline Pectinase & $77.27 \pm 3.441 \mathrm{~b}$ \\
Protease & $91.25 \pm 4.672 \mathrm{a}$ \\
Pectin lyase & $2.22 \pm 0.102 \mathrm{c}$ \\
Cellulase & $0.08 \pm 0.009 \mathrm{c}$ \\
\hline
\end{tabular}

Data are presented as mean \pm standard error (SE) of three independent experiments performed in triplicate. Different letters indicate a significant difference according to Duncan's multiple range test $(p<0.05)$.

significantly reduced the activity of pectinase, protease, pectin lyase and cellulase by an average of $33.8 \%$, $43.4 \%, 67.7 \%$ and $46.9 \%$, respectively, compared to control (Figure 1A-1D).

\section{Effect of SA on severity and reduction of soft rot of potato tubers}

Our results showed that SA-treated tubers had $<30 \%$ rot 2 weeks after inoculation compared to untreated tubers, with a disease incidence of $44.40 \%$ (Figure $2 \mathrm{~B}$ ). When compared to strain PC3-treated tubers, SA-treated tubers exhibit a decrease in DI of $27.80 \%$ and $44.40 \%$ after 7 and 14 DAI, respectively (Figure 2G). When compared to control, SA treatments across the four concentrations ( $0.5 \mathrm{mM}, 1.0 \mathrm{mM}, 1.5 \mathrm{mM}$ and $2.0 \mathrm{mM}$ ) reduced DI by an average of $47.5 \%$ and $54.7 \%$ at 7 days and 14 days, respectively (Figure $2 \mathrm{H}$ ).

\section{The action of SA on the growth of potato plant}

Our results showed that strain PC3-treated plant reduced plant height, the number of leaves, leaf area, fresh weight and dry weight by $13.7 \%, 19 \%, 25 \%, 15 \%$ and $27 \%$, respectively, compared to control (Figure 3A). However, foliar spraying of SA across the four concentrations increased plant height, the number of leaves, leaf area, fresh weight and dry weight by $47.8 \%, 22.8 \%, 13.5 \%$, $16.3 \%$ and $18.3 \%$, respectively, compared to control (Figure 3A-3E).

\section{Chlorophyll and carotenoid content in leaves}

Our results show that plants inoculated with strain PC3 reduced chlorophyll $a$ and $b$, total chlorophyll and carotenoid contents by $38.6 \%, 67.3 \%, 50.7 \%$ and $61.8 \%$, respectively, compared to control (Figure 4A-4D). However, foliar application of SA across the four concentrations $(0.5 \mathrm{mM}$, $1.0 \mathrm{mM}, 1.5 \mathrm{mM}$ and $2.0 \mathrm{mM})$ significantly $(p<0.05)$ increased chlorophyll $a$ and $b$, total chlorophyll and carotenoid contents by an average of $45.3 \%, 50.7 \%$, $52.7 \%$ and $71.8 \%$, respectively, compared to control (Figure 4A-4D).

\section{Effects of $\mathrm{SA}$ on $\mathrm{MDA}$ and $\mathrm{H}_{2} \mathrm{O}_{2}$ content in the leaves of potato plants}

Our results show that plants treated with strain PC3 increased MDA and $\mathrm{H}_{2} \mathrm{O}_{2}$ by $29 \%$ and $45 \%$, respectively compared to control. However, foliar application of SA to plants inoculated with $L$. amnigena significantly $(p<0.05)$ reduced MDA and $\mathrm{H}_{2} \mathrm{O}_{2}$ content across the four concentrations $(0.5 \mathrm{mM}, 1.0 \mathrm{mM}, 1.5 \mathrm{mM}$ and $2.0 \mathrm{mM}$ ) by an average of $47.0 \%$ and $47.5 \%$, respectively compared to control (Figure 5A-5B). The correlation matrix among chlorophyll, carotenoid, MDA and $\mathrm{H}_{2} \mathrm{O}_{2}$ contents is presented in Table $4 . \mathrm{H}_{2} \mathrm{O}_{2}$ showed a significant and negative correlation with chlorophyll $(r=-0.948)$, and carotenoid $(r=-0.884)$. MDA was significantly and negatively correlated with chlorophyll $(r=-0.985)$ and carotenoid $(r=-0.951)$. Moreover, carotenoid showed a significant and positive correlation with chlorophyll ( $r=0.987)$, MDA was significantly and positively correlated with $\mathrm{H}_{2} \mathrm{O}_{2}(r=0.975)$.

\section{Antioxidant enzyme activities in potato leaves}

Our results show that the plants treated with strain PC3 initially increased the activities of SOD, POD, CAT and PPO by $32.1 \%, 27.1 \%, 38.6 \%$ and $47.5 \%$, respectively, compared to control. The activity of SOD, POD, CAT and PPO across the four concentrations $(0.5 \mathrm{mM}$, $1.0 \mathrm{mM}, 1.5 \mathrm{mM}$ and $2.0 \mathrm{mM}$ ) was significantly $(p<0.05)$ increased by an average of $69.9 \%, 59.3 \%$, $63.9 \%$ and $68.6 \%$, respectively, compared to control (Figure 6A-6D). 

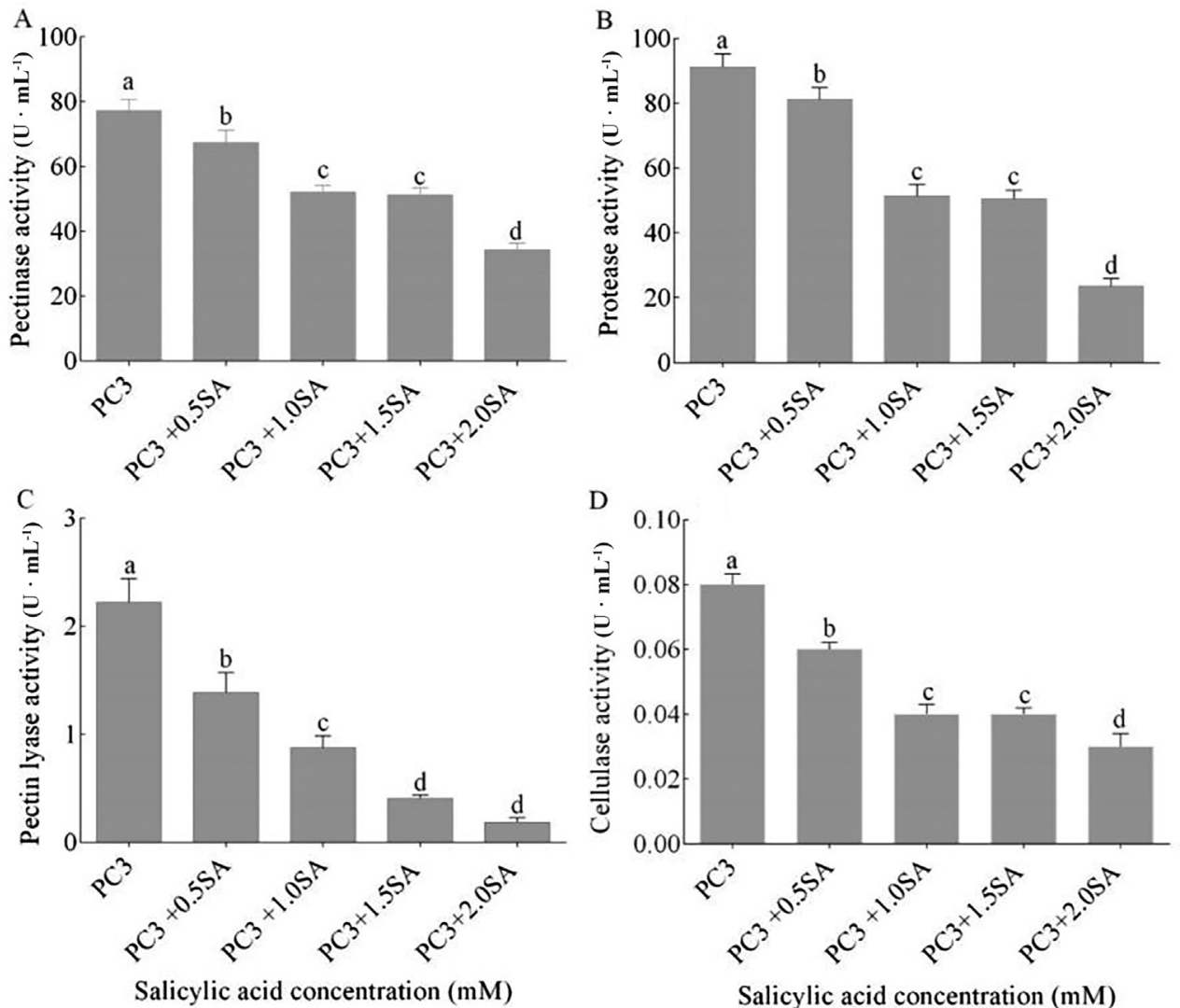

Figure 1. Effect of SA on (A) pectinase, (B) protease, (C) pectin lyase and (D) cellulase production of L. amnigena (Strain PC3) stress. Data are presented as mean \pm SE. Different letters indicate a significant difference according to Duncan's multiple range test $(p<0.05)$. SA, salicylic acid.

\section{Effect of SA on antioxidant gene expression}

Our results show that inoculation of L. amnigena to potato plants initially increased gene expression of SOD, POD, CAT, and GST. However, treatment with SA induced transcriptional levels of the SOD, POD, CAT and GST gene expression across the four concentrations ( $0.5 \mathrm{mM}, 1.0 \mathrm{mM}, 1.5 \mathrm{mM}$ and, $2.0 \mathrm{mM}$ ) by an average of 3.87, 3.25, 3.97 and 3.94-fold, respectively, compared to control (Figure 7A-7D).

\section{DISCUSSION}

Our study has shown that L. amnigena secretes extracellular enzymes (pectinase, protease, cellulase and pectin lyase) to cause potato soft rot in tubers. Our results are in agreement with Reeleder and Brammal (1994) and Prathyusha and Suneetha (2011), who revealed that many phytopathogens produce extracellular enzymes to invade plants, causing soft rot diseases both in the field and storage. Again, the secretion of the aforementioned enzymes, by L. amnigena contributed to the maceration of parenchyma cells and this finding is in line with the study by Popović et al. (2017) who discovered Pectobacterium atrosepticum causing bacterial soft rot on calla lily via exoenzyme production. However, when the pathogen was treated with SA, a reduction was noticed in the secretion of the extracellular enzyme. The colonies of L. amnigena in the absence of SA were flat with a rough appearance displaying irregular colony edges. Bacteria that were grown with the SA were incapable of producing flat and long zones, twitching zones and had round, smooth, regular colony edges, and short colony growth which may reduce their mode of infection and spreading within tissues. Therefore treatment of the pathogen with SA could reduce/block the pathway in which $L$. amnigena secretes these extracellular enzymes.

Our results showed that the application of 1.5 $2.0 \mathrm{mM} \mathrm{SA}$ solution significantly reduced the severity of soft rot in potato tubers 7 days and 14 DAI compared to the untreated tubers, confirming the induction of systemic resistance. Our results again indicated that treatments of potato soft rot disease with SA are a result of the association between the extracellular enzymes and the inhibitor sensitivity of SA. The reduced activity of extracellular enzymes decreased the potato soft rot and induced potato tuber resistance to L. amnigena. Our finding is consistent with Bawa et al. (2019) who reported that application of SA reduced disease severity and induced resistance to Fusarium solani in soybean seedlings. A study by Li and Zou (2017) indicated that foliar spraying of tomato plants with SA at a concentration of $2.0 \mathrm{mM}$ led to a significant reduction in disease severity. Similarly, our study also showed that 


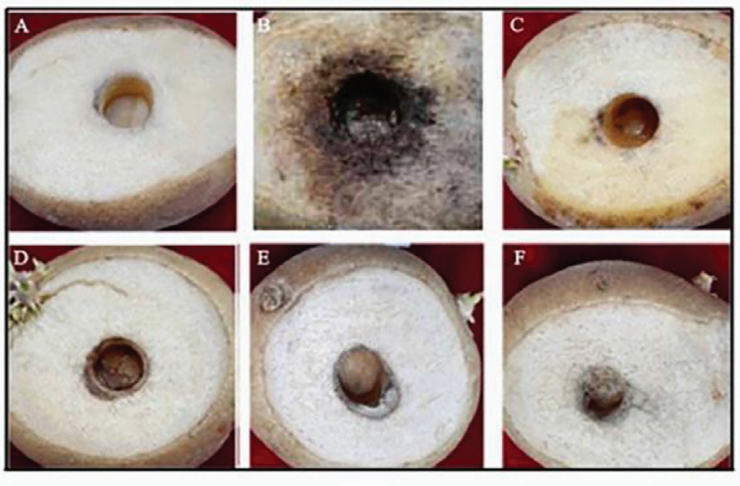

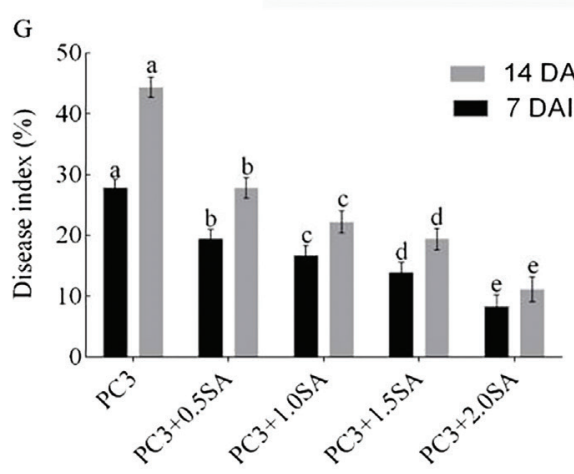

Salicylic acid concentration $(\mathrm{mM})$

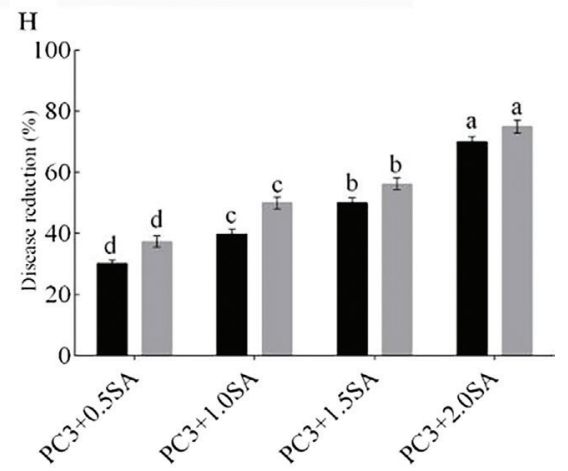

Salicylic acid concentration ( $\mathrm{mM})$

Figure 2. Symptoms of artificial infection with strain PC3 14 DAI. Tubers were treated with SA $24 \mathrm{~h}$ before inoculation with strain PC3. (A) Control (CK), (B) strain PC3 (C) 0.5 + PC3, (D) $1.0+$ PC3, (E) $1.5+$ PC3, (F) 2.0 + PC3. (G) DI $(\mathrm{H})$ Disease reduction. Data are presented as mean \pm SE. Different letters indicate a significant difference according to Duncan's multiple range test $(p<0.05)$. Potato tubers were treated with different concentrations of SA for $24 \mathrm{~h}$ before inoculation with strain PC3. The treatments were water (negative control), strain PC3 (positive control), PC3 + $0.5 \mathrm{mM}$ SA, PC3 + 1.0 mM SA, PC3 + 1.5 mM SA, PC3 + 2.0 mM SA. Strain PC3: L. amnigena, DAI. Figure 2A, tuber treated with distilled water showed no signs of rot, Figure 2B tuber inoculated with L. amnigena without SA treatment showed the highest signs of rot. Figure 2C-2F, tubers inoculated with L. amnigena and treated with different concentrations of SA showed minor signs of rot with Figure $2 \mathrm{~F}$ showing very little sign of rot. DAI, days after inoculation; DI, disease index; SA, salicylic acid.

the application of SA at $2.0 \mathrm{mM}$ induces better disease resistance of potato tubers against L. amnigena. Our findings suggest that SA can greatly improve disease resistance in potato tubers and that SA treatment can replace the use of synthetic bactericides in the control of soft rot in potato tubers.

Foliar application of SA significantly increased plant height, leaf area, leaf number and fresh and dry weights compared to untreated plants. It was found that inoculation of $L$. amnigena decreased the growth parameters of the potato plants. However, co-inoculation of SA with the pathogen improved the growth parameters compared to the control plants. These findings were due to the bactericidal effect of SA through the mechanism of growth promotion and inhibition of L. amnigena extracellular enzymes production. In the same context, a study by Al-Jeboori et al. (2017) showed that spraying potato plants with SA at a concentration of $100 \mathrm{mg} \cdot \mathrm{L}^{-1}$ resulted in the highest significant plant height values. Our findings are consistent with Amin et al. (2008) who reported that SA increases cell division in the meristem of wheat seedlings and improves plant growth.
Photosynthesis is an important physiological mechanism for enhancing plant survival by utilising light energy and synthesising organic compounds in plants $\mathrm{Xu}$ et al., 2014). The effectiveness of photosynthesis depends on chlorophyll content, but reactive oxygen species (ROS) can cause a noticeable decrease in chlorophyll content in plants due to their sensitive nature (Van Oosten et al., 2017). Total chlorophyll content can be used as an indicator in the determining the effects of supplements on plant metabolism. In previous reports, SA application could cause an increase in total chlorophyll content (Baghizadeh et al., 2014). Our results are in agreement with these findings with an increase in chlorophyll content by SA application. Therefore, plant survival, development and production are primarily dependent on improved chlorophyll content. Our results showed that foliar application of SA significantly increased chlorophyll and carotenoid content under control and $L$. amnigena stress. The infection of $L$. amnigena decreased the leaf number, leaf area, water and nutrient uptake which directly affected the chlorophyll and carotenoid content. However, the SA treatment through 

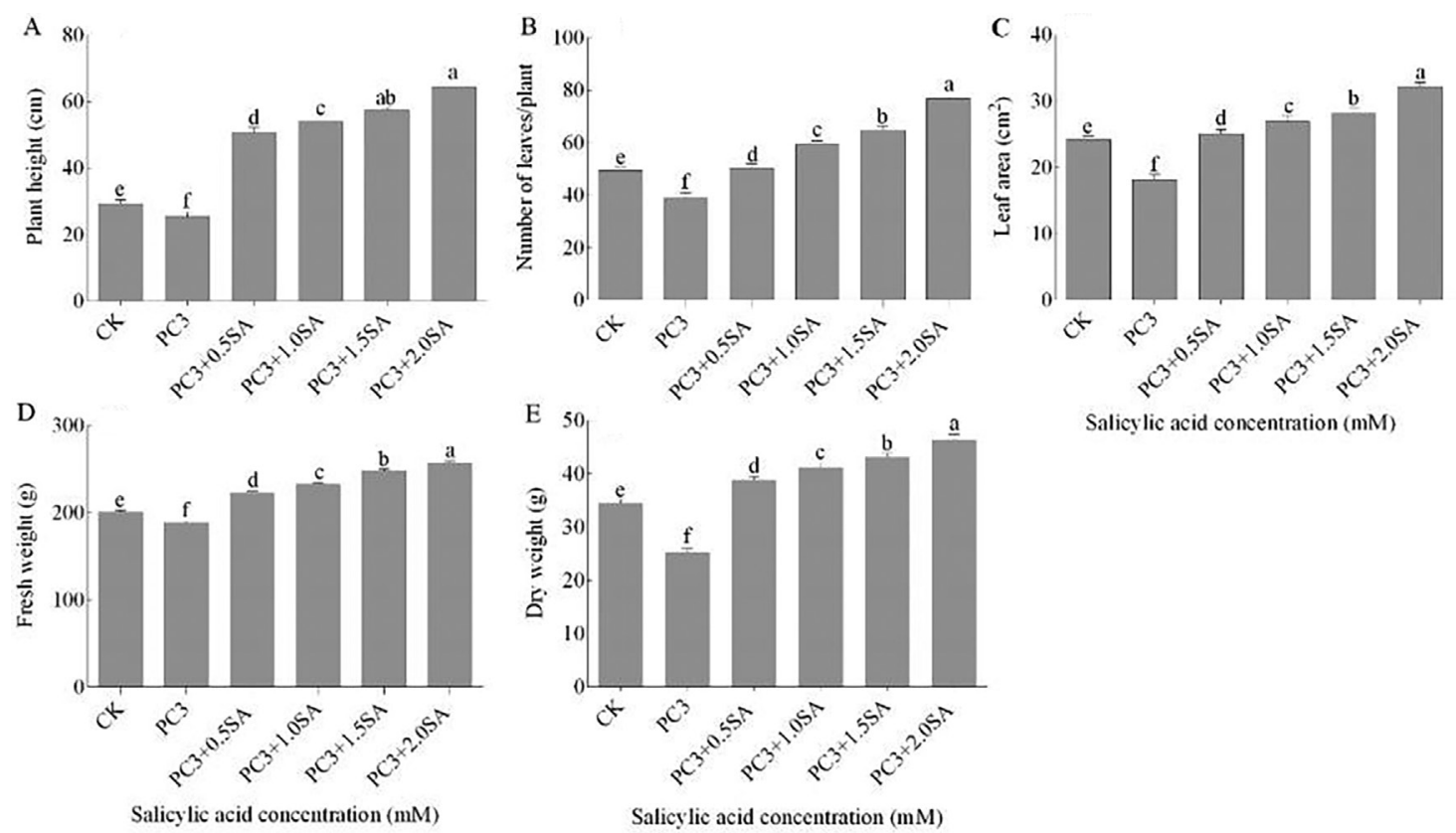

Salicylic acid concentration ( $\mathrm{mM}$ )

Figure 3. Effect of SA on (A) Plant height, (cm) (B) number of leaves, (C) leaf area $\left(\mathrm{cm}^{2}\right)$, (D) fresh weight $(\mathrm{g})$ and (E) dry weight (g) under L. amnigena (Strain PC3) stress, where CK represents control treatment with distilled water. Data represent mean $\pm \mathrm{SE}$ of three replicates. Lower case letters indicate statistical significance between treatments by least significant difference (LSD) test $(p<0.05)$. SA, salicylic acid.
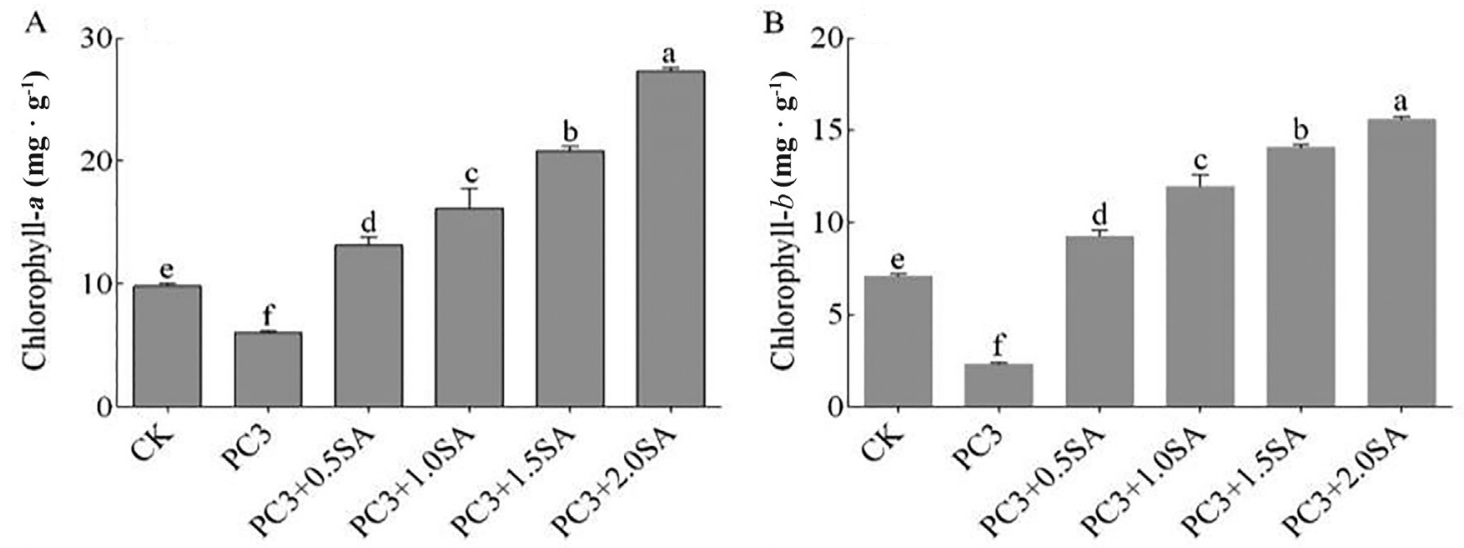

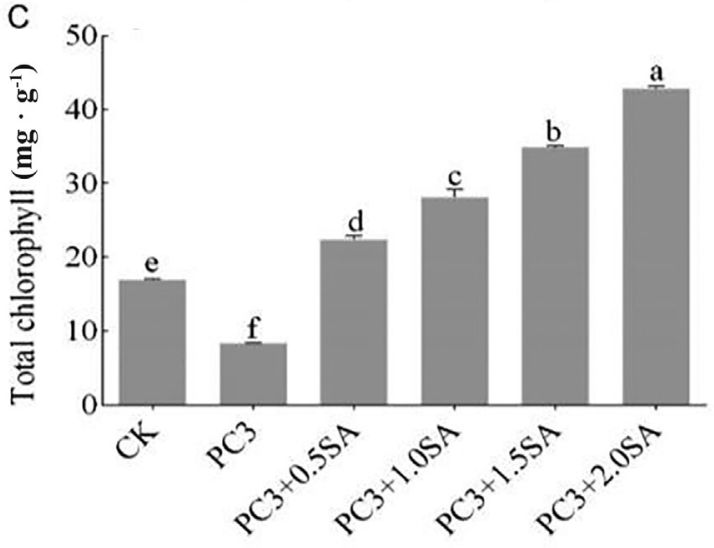

Salicylic acid concentration $(\mathrm{mM})$

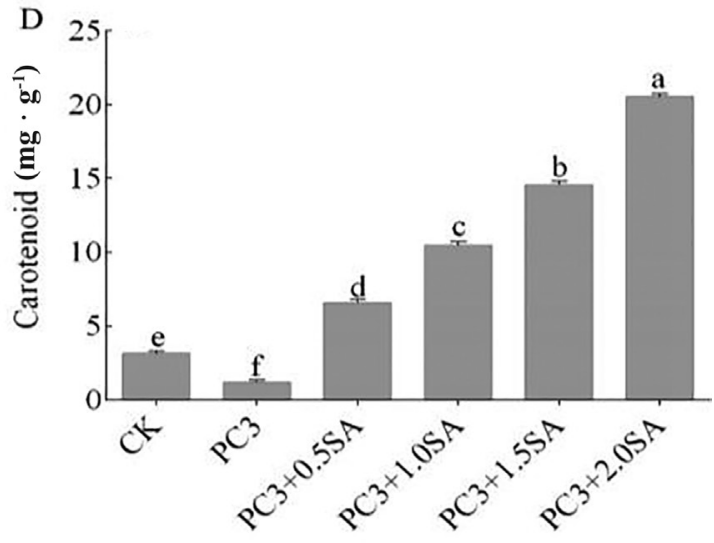

Salicylic acid concentration $(\mathrm{mM})$

Figure 4. Effect of SA on (A) chlorophyll $a$ (B) chlorophyll $b$, (C) total chlorophyll $a+b$, (D) carotenoid under L. amnigena (Strain PC3) stress, where CK represents control treatment with distilled water. Data represent mean \pm SE of three replicates. Lower case letters indicate statistical significance between treatments by LSD test $(p<0.05)$. SA, salicylic acid. 


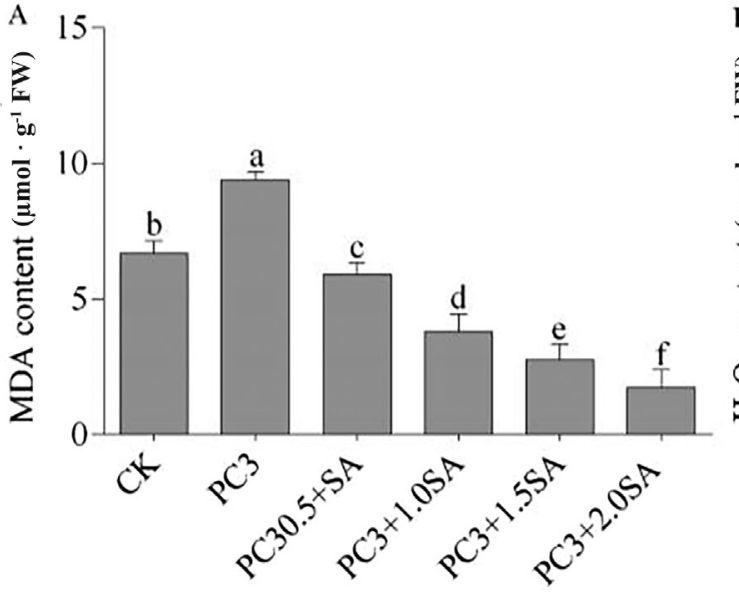

Salicylic acid concentration $(\mathrm{mM})$

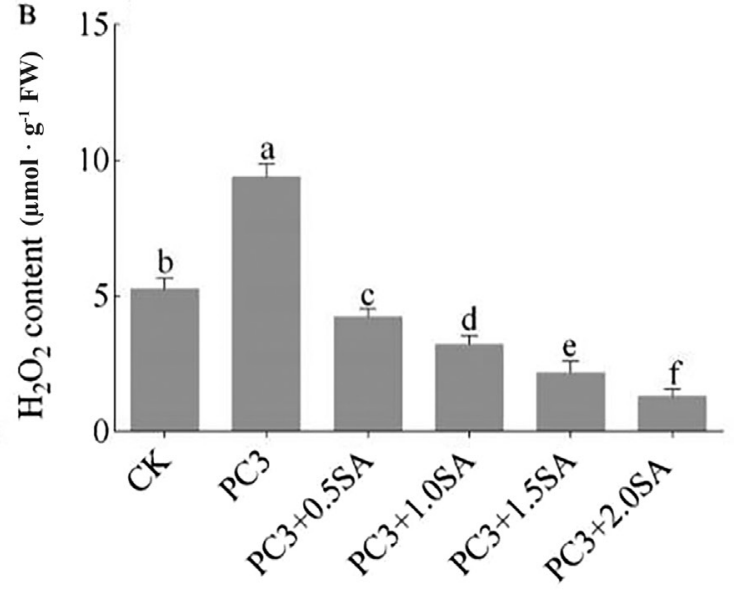

Salicylic acid concentration $(\mathrm{mM})$

Figure 5. Effect of SA on (A) MDA content, (B) $\mathrm{H}_{2} \mathrm{O}_{2}$ content of potato leaves under L. amnigena (Strain PC3) stress, where $\mathrm{CK}$ represents control treatment with distilled water. Data represent mean $\pm \mathrm{SE}$ of three replicates. Lower case letters indicate statistical significance between treatments by LSD test $(p<0.05) . \mathrm{H}_{2} \mathrm{O}_{2}$, hydrogen peroxide; MDA, malondialdehyde; SA, salicylic acid.

Table 4. Pearson's correlation matrix among some parameters measured in the plant.

\begin{tabular}{lcccc}
\hline Traits & Chlorophyll & $\mathrm{H}_{2} \mathrm{O}_{2}$ & MDA & Carotenoid \\
\hline Chlorophyll & - & & & \\
$\mathrm{H}_{2} \mathrm{O}_{2}$ & $-0.948^{* *}$ & - & & \\
MDA & $-0.985^{* *}$ & $0.975^{* *}$ & - & \\
Carotenoid & $0.987^{* *}$ & $-0.884^{*}$ & $-0.951^{* *}$ & -
\end{tabular}

*Means significant difference at $5 \%$

**Means significant difference at $1 \%$.

$\mathrm{H}_{2} \mathrm{O}_{2}$, hydrogen peroxide; MDA, malondialdehyde.

spraying reversed the aforementioned effects of the pathogen. Our results suggest that the application of SA decreased oxidative stress and increased the leaf surface area, and improved the closure and opening of the stomata which modulated carbon dioxide absorption. These facilitated photosynthetic activities of the plant. At the same time, a reduction in the activation of chlorophylldegrading enzymes was observed in previous studies using SA to enhance plant photosynthesis under different conditions (Van Oosten et al., 2017). The reduction of carotenoid content under stress has been associated with the degradation of $\beta$-carotene (Sultana et al., 1999). Under stress, the reduction of carotenoids could be related to their protective function in the photosynthetic apparatus, as carotenoids are responsible for scavenging ROS, preventing lipid peroxidation and ultimately mitigating oxidative stress (Koyro, 2006). Our results are in agreement with the findings of Shafiei et al. (2019) who reported that the application of $2 \mathrm{mM}$ SA mitigated the negative effects of stress in young olive trees by improving chlorophyll content, increasing total soluble carbohydrate and proline content of leaves, which may lead to osmotic adjustment.
MDA and $\mathrm{H}_{2} \mathrm{O}_{2}$ levels increased significantly in the treatment with $L$. amnigena compared with the water treatment and the treatments with SA in this study. Foliar application of SA reduced MDA and $\mathrm{H}_{2} \mathrm{O}_{2}$ levels in all cases when compared with the corresponding L. amnigena treatment. L. amnigena-stressed potato plants showed a higher accumulation of ROS content and thus suffered oxidative damage. Consequently, the increased $\mathrm{H}_{2} \mathrm{O}_{2}$ formation resulted in higher MDA content. While ROS can help improve the resistance of plant tissues to disease, high ROS levels can cause lipid peroxidation and lead to loss of membrane integrity of plant organs. Previous studies have demonstrated the effectiveness of SA treatment in reducing the lipid peroxidation level of plant tissues under stress compared to control plants (Hayat et al., 2007). Based on all the above results, the beneficial effects of treatments with SA could be attributed to the reduction in the accumulation of $\mathrm{H}_{2} \mathrm{O}_{2}$ and MDA levels, possibly by increasing the activity of antioxidant enzymes. Our results are in agreement with those of Sayyari et al. (2013) and Estaji (2020) who reported that application of SA significantly decreased MDA accumulation and $\mathrm{H}_{2} \mathrm{O}_{2}$ under drought stress.

The correlation results of our study showed that the physiological and molecular responses in potato plants under L. amnigena stress treated with SA have both positive and negative associations. MDA and $\mathrm{H}_{2} \mathrm{O}_{2}$ content in the leaves were found to be considerably higher, lowering chlorophyll and carotenoid contents. The content of MDA and $\mathrm{H}_{2} \mathrm{O}_{2}$ was shown to be strongly inversely related to the content of chlorophyll and carotenoid. Our results are consistent with those of Wei et al. (2021) who found that higher MDA and $\mathrm{H}_{2} \mathrm{O}_{2}$ content in wheat plants resulted in lower chlorophyll and carotenoid contents. 


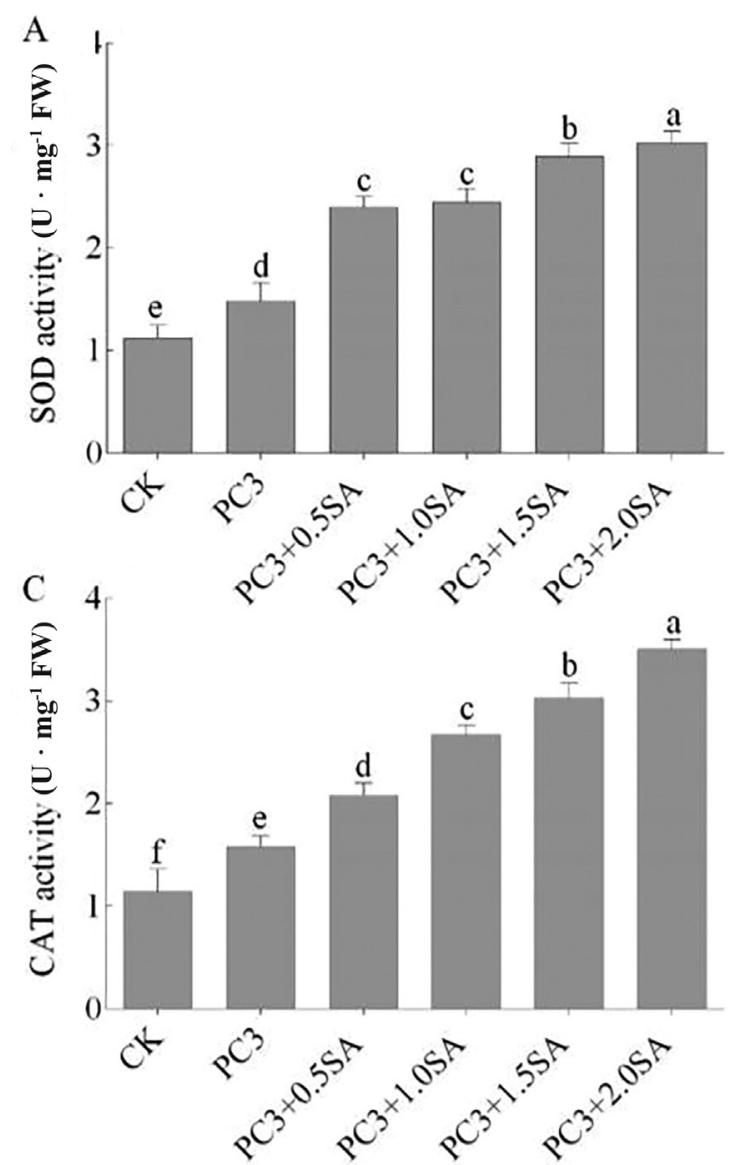

Salicylic acid concentration (mM)

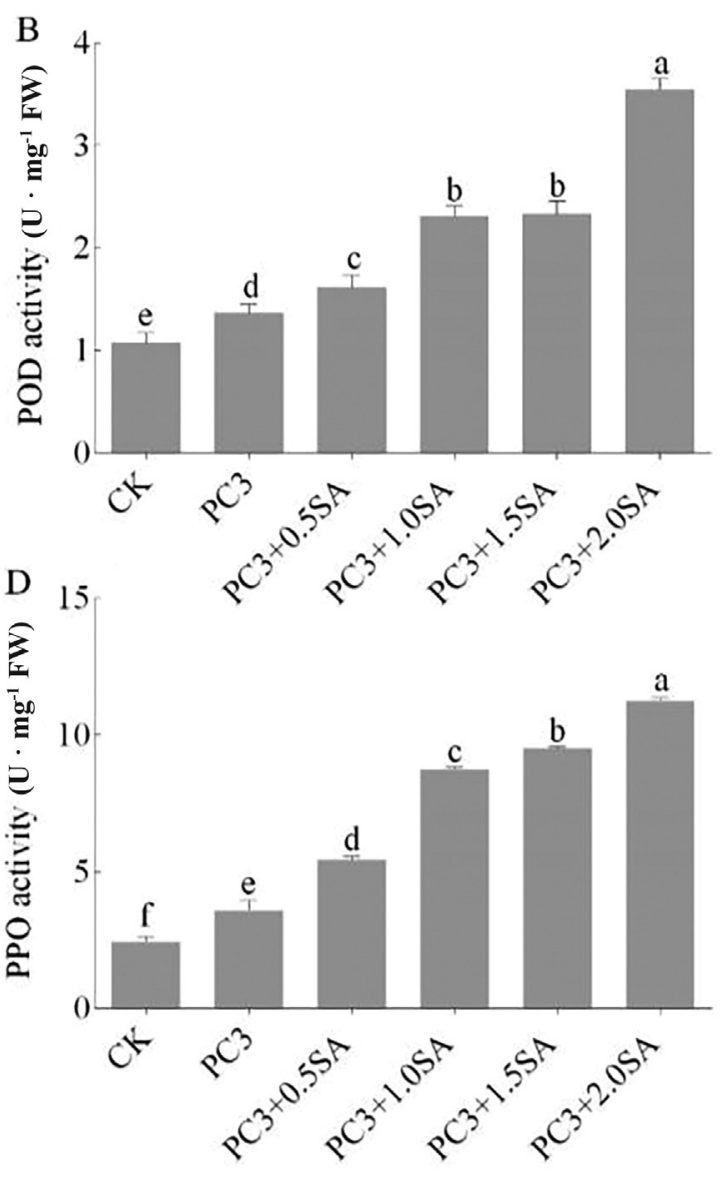

Salicylic acid concentration (mM)

Figure 6. Effect SA on (A) SOD activity, (B) POD activity, (C) CAT activity and (D) PPO activity of potato leaves under L. amnigena (Strain PC3) stress, where CK represents control treatment with distilled water. Data represent mean \pm SE of three replicates. Lower case letters indicate statistical significance between treatments by LSD test $(p<0.05)$. CAT, catalase; POD, peroxide; PPO, polyphenol oxidase; SA, salicylic acid; SOD, superoxide dismutase.

In our study, treatment with SA increased the activities of SOD, POD, PPO and CAT. It has been shown that SA plays a significant role in the induction of systemic acquired resistance (SAR) of plants (Hayat et al., 2010). In support to our findings, other previous studies also found that enzymatic and non-enzymatic antioxidants were increased during SA treatments on crop plant (Sofy, 2015; Chen et al., 2016; Razmi et al., 2017; Moharramnejad et al., 2019). However, the SA and L. amnigena combined treatment increased enzymatic activities higher than the control. The corresponding mechanism was that SA could move freely between cells, tissues and organs as a longrange mediator (Kumar, 2014), to stimulate the activities of one or more antioxidant enzymes and then increase plant tolerance to overcome oxidative stress induced by various biotic and abiotic stresses (Idrees et al., 2011; Ibrahim et al., 2017). Therefore, SA reduced excess ROS by up-regulating antioxidant protection systems during $L$. amnigena stress. Our study is consistent with the study of Shen et al. (2014) and Ma et al. (2017), who reported that SA significantly increased antioxidant enzyme activities under drought and salt stress.
It has been reported that exogenous SA application induced the expression of defence-related genes that were systematically activated after infection by tobacco mosaic virus (TMV) (Nandi and Babu, 2013). Similarly, our results showed that the level of expression of SOD, POD, CAT and GST genes in potato leaves under $L$. amnigena was increased by SA treatment compared to the control. Also, the transcription levels of SOD, POD, CAT and GST genes were significantly increased and up-regulated under L. amnigena stress, following the corresponding antioxidant enzyme activity indicating their role against oxidative stress. SA is an endogenous signal for the activation of certain plant defence responses, including pathogenesis-related (PR) gene expression and the establishment of stress resistance (Klessig et al., 2018). A significant increase in gene expression after SA application under pathogen stress helped to reverse the effects of pathogen-induced ROS on growth and photosynthesis. Our results are consistent with previous studies by Morris et al. (2000), who reported that SA treatment increases gene expression during leaf senescence. 

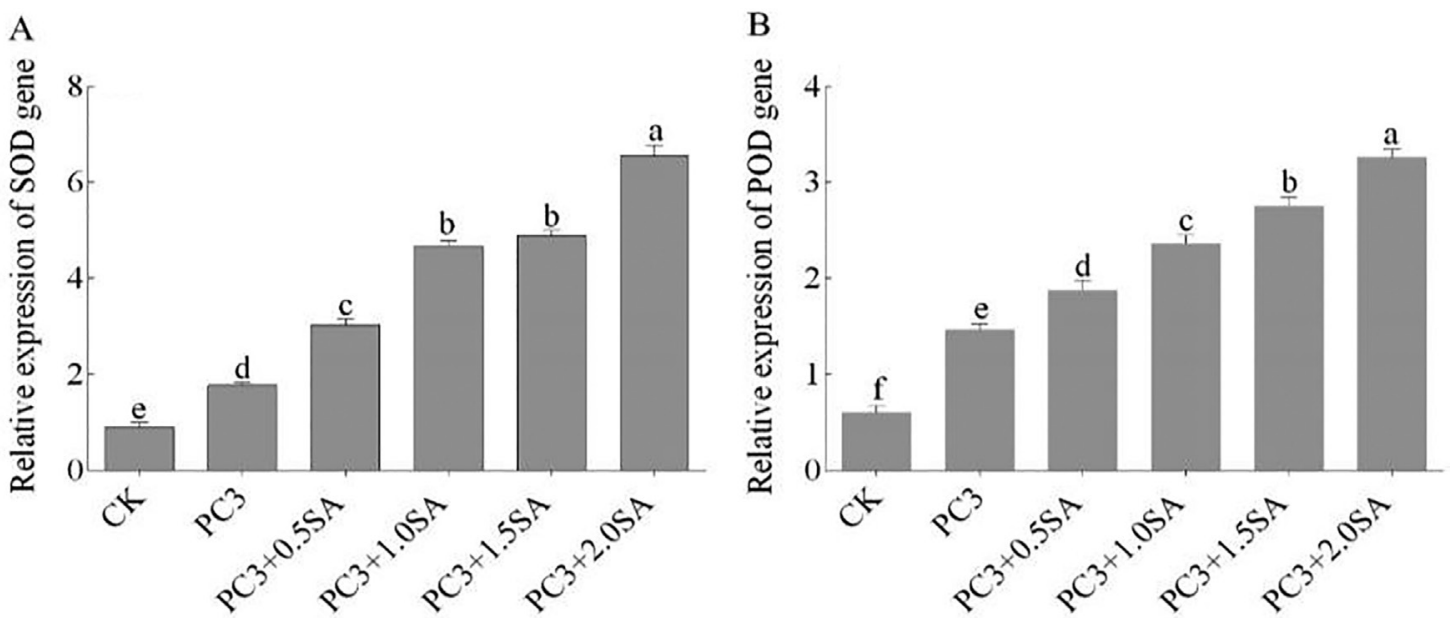

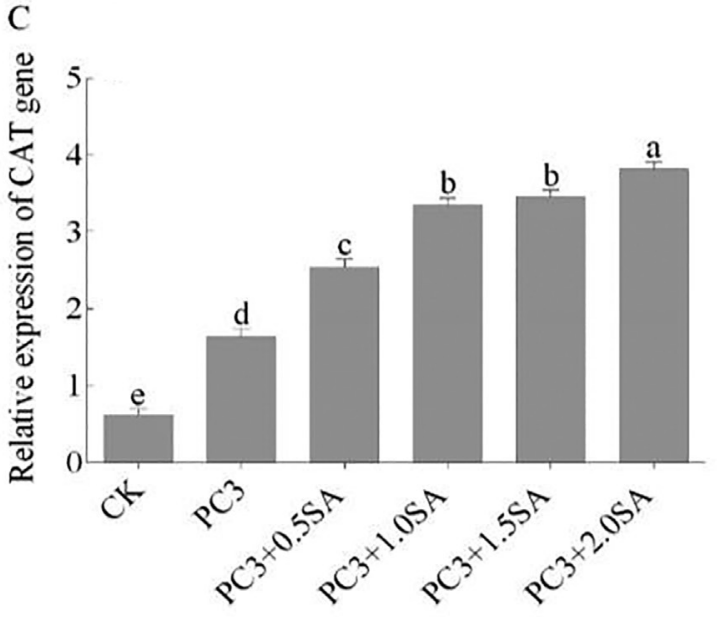

Salicylic acid concentration (mM)

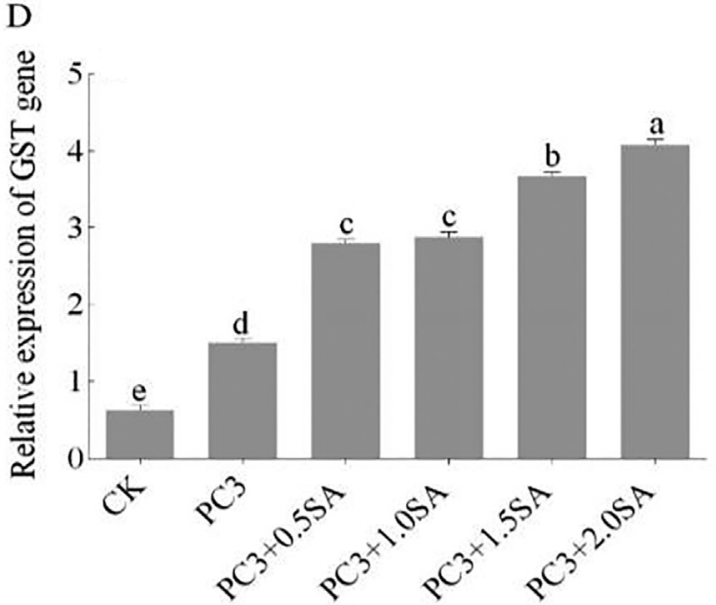

Salicylic acid concentration (mM)

Figure 7. Effect of SA on expression patterns of SOD (A), POD (B), CAT (C), and GST (D) in leaves of potato plants under L. amnigena (Strain PC3) stress, where CK represents control treatment with distilled water. Data represent mean $\pm \mathrm{SE}$ of three replicates. Lower case letters indicate statistical significance between treatments by LSD test $(p<0.05)$. CAT, catalase; GST, glutathione S-transferase; POD, peroxide; SA, salicylic acid; SOD, superoxide dismutase.

\section{CONCLUSIONS}

Our results suggest that SA is a plant growth-promoting hormone that can prime plant to tolerate stresses in vitro and in vivo, and induce defence in plant by attenuating the negative effects of pathogens. Rigorous physiological, biochemical and molecular assays used in the study allowed us to explore the possible mechanisms and pathways in which SA attenuates the suppressive effects of L. amnigena in both potato tuber and plant growth. The pathway include SA pathway. The mechanism involves are: (i) reduction in exoenzymes production, (ii) reduction of bacterial fission, growth and mobility (iii) antioxidant defence system and expression increase of plant growth. The reduced activity of extracellular enzymes from $1.5 \mathrm{mM}$ to $2.0 \mathrm{mM}$ SA also reduced pathogenicity in the tubers against soft rot, indicating that, the exogenously application of SA induces many defence responses of the plant that affect the invasion of plant pathogens. Carotenoids are pigments distributed throughout the plant that is necessary for photosynthesis and absorb energy from the sun's blue-green spectrum and transfer it to chlorophylls, thereby increasing the wavelength range of light. According to our findings, L. amnigena stress caused significant decreases in chlorophyll and carotenoid contents. Based on the results, foliar application SA $(1.5-2.0 \mathrm{mM})$ on potato plant leaves increased the chlorophyll and carotenoid content, also increased the activity of antioxidant enzymes and reduced oxidative stress (MDA and $\mathrm{H}_{2} \mathrm{O}_{2}$ ) thereby increasing plants defence stress. Management of soft rot disease in potato tubers caused by L amnigena can be considered based on our results using a threshold from $1.5 \mathrm{mM}$ to $2.0 \mathrm{mM}$ SA before storage or planting. Extended field trials are needed to further optimise the use of SA to control soft rot caused by L. amnigena. 


\section{ACKNOWLEDGEMENT}

The authors would like to show appreciation to the teachers and students in the laboratory for their help and support during the experiment and article writing process.

\section{FUNDING}

This work was supported by The Science and Technology Innovation Fund of Gansu Agricultural University (No. GAU-XKJS-2018-148) and The Project of National Potato Industry Technology System (No. CARS-10-P18).

\section{AUTHOR CONTRIBUTIONS}

All authors contributed extensively to the work presented in this article. R.O, C.Y. and S.B. designed the experiment. S.B and L.C. assembled input data and L.W. wrote code. R.O., M.J and S.B. analysed output data. C.Y. provided experiment material. R.O. administered the experiments and wrote the manuscript.

\section{CONFLICT OF INTEREST}

The authors declare that there is no conflict of interest.

\section{REFERENCES}

ABd EL-KahiR, H. (2004). Efficacy of starner in controlling the bacterial soft rot pathogen in onion. Journal of Advanced Agriculture Research, 49, 721-731.

Abd-Elhafeez, E., Alkhazindar, M, and Sayed E. (2018). Isolation and characterization of Enterobacter strains causing potato soft rot disease in Egypt. Minia Science Bulletin, 29, 1-13.

Al-Jeboori, K., Al-Mharib, M., Hamdan, A., And MAHMOOD, A. (2017). Effect of irrigation intervals and foliar of salicylic acid on growth and yield of potato. The Iraqi Journal of Agricultural Science, 48, 242-247.

Al-Kharousi, Z. S., Guizani, N., Al-Sadi, A. M., Al-Bulushi, I. M., And Shaharoona, B. (2016). Hiding in fresh fruits and vegetables: Opportunistic pathogens may cross geographical barriers. International Journal of Microbiology, 2016, 4292417, doi: 10.1155/2016/4292417.

Amin, A., Rashad, E. S. M., and Gharib, F. A. (2008). Changes in morphological, physiological and reproductive characters of wheat plants as affected by foliar application with salicylic acid and ascorbic acid. Australian Journal of Basic Applied Sciences, 2, 252-261.

Aymen, E. M. (2018). Seed priming with plant growth regulators to improve crop abiotic stress tolerance. In A. Rakshit and H. Singh (Eds), Advances in seed priming (pp. 95-106). Singapore: Springer.

Baghizadeh, A., Salarizadeh, M. R., and Abaasi, F. (2014). Effects of salicylic acid on some physiological and biochemical parameters of Brassica napus L. (canola) under salt stress. International Journal of Agricultural Science, 4(2), 147-152.

Barras, F., Van Gijsegem, F., and Chatterjee, A. K. (1994). Extracellular enzymes and pathogenesis of soft-rot Erwinia. Annual Review of Phytopathology, 32, 201-234.

Bateman, D. (2012). Plant cell wall hydrolysis by pathogens. In J. Friend and D. R. Threlfall (Eds), Biochemical aspects of plant-parasite relationships (pp. 79-103). London, UK: Academic Press.

Bawa, G., Feng, L., Yan, L, Du, Y., Shang, J., Sun, X., Wang, X., Yu, L., Liu, C., And Yang, W. (2019). Pretreatment of salicylic acid enhances resistance of soybean seedlings to Fusarium solani. Physics in Medicine and Biology, 101, 315-323.

Ben-David, A., And Davidson, C. E. (2014). Estimation method for serial dilution experiments. Journal of Microbiological Methods, 107, 214-221.

CAO, J., YAN, J., ZHAO, Y., AND JIANG, W. (2013). Effects of postharvest salicylic acid dipping on Alternaria rot and disease resistance of jujube fruit during storage. Journal of the Science of Food and Agriculture, 93, 3252-3258.

Chen, Y., Cui, J., Li, G., Yuan, M., Zhang, Z., Yuan, S., AND ZHANG, H. (2016). Effect of salicylic acid on the antioxidant system and photosystem II in wheat seedlings. Biologia Plantarum, 60, 139-147.

Collmer, A., Berman, P., And Mount, M. (2012). Pectase lyase regulation and bacterial soft-rot pathogenesis. Phytopathogenic Prokaryotes 1, 395-422.

Czajkowski, R., Perombelon, M. C., Van Veen, J. A., and Van Der Wolf, J. M. (2011). Control of blackleg and tuber soft rot of potato caused by Pectobacterium and Dickeya species: A review. Plant Pathology, 60, 999-1013.

Dutt, S., Manjul, A. S., Raigond, P., Singh, B., Siddappa, S., Bhardwaj, V., Kawar, P. G., Patil, V. U., and Kardile, H. B. (2017). Key players associated with tuberization in potato: Potential candidates for genetic engineering. Critical Reviews in Biotechnology, 37, 942-957.

EstAJI, A. (2020). Impact of exogenous applications of salicylic acid on the tolerance to drought stress in pepper (Capsicum annuum L.) plants. Research Square, doi: 10.21203/rs.3.rs-116192/v1.

Hayat, Q., Hayat, S., Irfan, M., and Ahmad, A. (2010). Effect of exogenous salicylic acid under changing environment: A review. Environmental Experimental Botany, 68, 14-25.

Hayat, S., Ali, B., And Ahmad, A. (2007). Salicylic acid: Biosynthesis, metabolism and physiological role in plants. In S. Hayat and A. Ahmad (Eds), Salicylic acid: A plant hormone (pp. 1-14). Dordrecht, The Netherlands: Springer.

Hungund, B. S., And Gupta, S. G. (2010). Production of bacterial cellulose from Enterobacter amnigenus GH-1 isolated from rotten apple. World Journal of Microbiology and Biotechnology, 26(10), 1823-1828.

IBrahim, M. H., OMAR, H., ANd Zain, N. A. M. (2017). Salicylic acid enhanced photosynthesis, secondary 
metabolites, antioxidant and lipoxygenase inhibitory activity (LOX) in Centella asiatica. Annual Research Review in Biology, 17(4), RRB.36153, doi: 10.9734/ ARRB/2017/36153.

Idrees, M., Naeem, M., Aftab, T., And Khan, M. M. A. (2011). Salicylic acid mitigates salinity stress by improving antioxidant defense system and enhances vincristine and vinblastine alkaloids production in periwinkle [Catharanthus roseus (L.) G. Don]. Acta Physiologiae Plantarum, 33, 987-999.

Jayakannan, M., Bose, J., Babourina, O., Rengel, Z., and Shabala, S. (2015). Salicylic acid in plant salinity stress signaling and tolerance. Plant Growth Regulation, 76, 25-40.

Jess, S., Kildea, S., Moody, A., Rennick, G., Murchie, A. K., AND Cooke, L. R. (2014). European Union policy on pesticides: Implications for agriculture in Ireland. Pest Management Science, 70, 1646-1654.

KazAN, K. (2015). Diverse roles of jasmonates and ethylene in abiotic stress tolerance. Trends in Plant Science, 20, 219-229.

Klessig, D. F., Choi, H. W., And Dempsey, D. M. A. (2018). Systemic acquired resistance and salicylic acid: Past, present, and future. Molecular PlantMicrobe Interactions, 31, 871-888.

Koo, Y. M., Heo, A. Y., And Chol, H. W. (2020). Salicylic acid as a safe plant protector and growth regulator. The Plant Pathology Journal, 36(1), doi: 10.5423/ PPJ.RW.12.2019.0295.

Koyro, H. W. (2006). Effect of salinity on growth, photosynthesis, water relations and solute composition of the potential cash crop halophyte Plantago coronopus (L.). Environmental Experimental Botany, 56, 136-146.

Kubalt, K. (2016). The role of phenolic compounds in plant resistance. Biotechnology and Food Sciences, 80(2), 97-108.

Kumar, D. (2014). Salicylic acid signaling in disease resistance. Plant Science, 228, 127-134.

LI, L., AND Zou, Y. (2017). Induction of disease resistance by salicylic acid and calcium ion against Botrytis cinerea in tomato (Lycopersicon esculentum). Emirates Journal of Food Agriculture, 29(1), 78-82.

Lichtenthaler, H. K. (1987). Chlorophylls and carotenoids: Pigments of photosynthetic biomembranes. Methods in Enzymology, 148, 350-382.

Liu, S., TAng, Y., Wang, D., Lin, N., And Zhou, J. (2016). Identification and characterization of a New Enterobacter onion bulb decay caused by Lelliottia amnigena in China. Applied Microbiology, 2(2), 1000114, doi: 10.4172/2471-9315.1000114.

Livak, K. J., And Schmittgen, T. D. (2001). Analysis of relative gene expression data using real-time quantitative PCR and the $2^{-\Delta \Delta C T}$ method. Methods, 25, 402-408.

Ma, X., Zheng, J., Zhang, X., Hu, Q., AND Qian, R. (2017). Salicylic acid alleviates the adverse effects of salt stress on Dianthus superbus (Caryophyllaceae) by activating photosynthesis, protecting morphological structure, and enhancing the antioxidant system. Frontiers in Plant Science, 8, doi: 10.3389/ fpls.2017.00600.

Manzira, C. (2010). Potato production handbook. Harare, Zimbabwe: Potato Seed Association, Zimbabwe Publishers.

Mateo, A., Funck, D., Mühlenbock, P., Kular, B., Mullineaux, P. M., And Karpinski, S. (2006). Controlled levels of salicylic acid are required for optimal photosynthesis and redox homeostasis. Journal of Experimental Botany, 57(8), 1795-1807.

Mauch-Mani, B., Baccelli, I., Luna, E., And Flors, V. (2017). Defense priming: An adaptive part of induced resistance. Annual Review of Plant Biology, 68, 485-512.

Moharramnejad, S., Sofalian, O., Valizadeh, M., Asgari, A., Shiri, M. R., and Ashraf, M. (2019). Response of maize to field drought stress: Oxidative defense system, osmolytes' accumulation and photosynthetic pigments. Pakistan Journal of Botany, 51, 799-807.

Morris, K., Mackerness, S. A. H., Page, T., John, C. F., Murphy, A. M., Carr, J. P., AND Buchanan-Wollaston, V. (2000). Salicylic acid has a role in regulating gene expression during leaf senescence. The Plant Journal, 23, 677-685.

NANDI, B., AND BABU, S. S. (2013). Mechanism of action of salicylic acid during defense response of plant. Indian Journal of Scientific Research, 4, 101-105.

Pérombelon, M. (2002). Potato diseases caused by soft rot Erwinias: An overview of pathogenesis. Plant Pathology, 51, 1-12.

Popović, T., Jelušić, A., Milovanović, P., Janjatović, S., Budnar, M., Dimkić, I., and Stanković, S. (2017). First report of Pectobacterium atrosepticum, causing bacterial soft rot on calla lily in Serbia. Plant Disease, 101, 21-45.

Prathyusha, K., and Suneetha, V. (2011). Bacterial pectinases and their potent biotechnological application in fruit processing/juice production industry: A review. Journal of Phytology, 3, 16-19.

Rahaman, M. M., and Shehab, M. K. (2019). Water consumption, land use and production patterns of rice, wheat and potato in South Asia during 19882012. Sustainable Water Resources Management, 5, 1677-1694.

Razmi, N., Ebadi, A., Daneshian, J., And Jahanbakhsh, S. (2017). Salicylic acid induced changes on antioxidant capacity, pigments and grain yield of soybean genotypes in water deficit condition. Journal of Plant Interactions, 12, 457-464.

Reeleder, R., and Brammall, R. (1994). Pathogenicity of Pythium species, Cylindrocarpon destructans, and Rhizoctonia solani to ginseng seedlings in Ontario. Canadian Journal of Plant Pathology, 16, 311-316.

Sayyari, M., Ghavami, M., Ghanbari, F., And Kordi, S. (2013). Assessment of salicylic acid impacts on growth 
rate and some physiological parameters of lettuce plants under drought stress conditions. International Journal of Agriculture Crop Sciences, 5(17), 1951-1957.

Scherf, J. M., Milling, A., And Allen, C. (2010). Moderate temperature fluctuations rapidly reduce the viability of Ralstonia solanacearum race 3, biovar 2, in infected geranium, tomato, and potato plants. Applied Environment Microbiology, 76, 7061-7067.

Shafiei, N., Khaleghi, E., and Moallemi, N. (2019). Effect of salicylic acid on some morphological and biochemical characteristics of olive (Olea europaea cv. 'Konservalia') under water stress. Journal of Plant Productions, 42, 15-30.

Shen, C., Hu, Y., Du, X., Li, T., TAng, H., And Wu, J. (2014). Salicylic acid induces physiological and biochemical changes in Torreya grandis cv. Merrillii seedlings under drought stress. Trees, 28, 961-970.

Silva, T. R, Duarte, A. W. F., and Passarini, M. R. Z. (2018). Bacteria from Antarctic environments: Diversity and detection of antimicrobial, antiproliferative, and antiparasitic activities. Polar Biology, 41, 1505-1519.

Sofy, M. (2015). Application of salicylic acid and zinc improves wheat yield through physiological processes under different levels of irrigation intervals. International Journal of Plant Research, 5, 136-156.

Sultana, N., Ikeda, T., and Itoh, R. (1999). Effect of $\mathrm{NaCl}$ salinity on photosynthesis and dry matter accumulation in developing rice grains. Environmental Experimental Botany, 42, 211-220.

Toth, I. K., Bell, K. S., Holeva, M. C., And Birch, P. R. (2003). Soft rot Erwiniae: From genes to genomes. Molecular Plant Pathology, 4, 17-30.

Van Oosten, M. J., Pepe, O., De Pascale, S., Silletti, S., And Maggio, A. (2017). The role of biostimulants and bioeffectors as alleviators of abiotic stress in crop plants. Chemical. Biological Technologies in Agriculture, 4, 1-12.

Vlot, A. C., Dempsey, D. A., And Klessig D. F. (2009). Salicylic acid, a multifaceted hormone to combat disease. Annual Review in Phytopathology, 47, 177-206.

WANG, L. J., AND LI, S. H. (2006). Salicylic acid-induced heat or cold tolerance in relation to $\mathrm{Ca}^{2+}$ homeostasis and antioxidant systems in young grape plants. Plant Science, 170, 685-694.

Wang, N., Reidsma, P., Pronk, A., De Wit, A., And VAn Ittersum, M. (2018). Can potato add to China's food self-sufficiency? The scope for increasing potato production in China. European Journal of Agronomy, 101, 20-29.

Wei, C., Jiao, Q., Agathokleous, E., Liu, H., Li, G., Zhang, J. FAHAD, S. AND JiAnG, Y. (2021). Hormetic effects of zinc on growth and antioxidant defense system of wheat plants. Science of The Total Environment, doi: 10.1016/j.scitotenv.2021.150992.

Xie, C., Wang, C., Wang, X., and Yang, X. (2013). Two modified RNA extraction methods compatible with transcript profiling and gene expression analysis for cotton roots. Preparative Biochemistry Biotechnology, 43, 500-511.

Xu, W. Z., Deng, X. P., Xu, B. C., Gao, Z. J., And Ding, W. L. (2014). Photosynthetic activity and efficiency of Bothriochloa ischaemum and Lespedeza davurica in mixtures across growth periods under water stress. Acta Physiologiae Plantarum, 36, 1033-1044.

Yousif, D. Y. (2018). Effects sprayed solution of salicylic acid to prevent of wilt disease caused by Fussarium oxysporium. Journal of Physics: Conference Series, 1003, 012001, doi: 10.1088/17426596/1003/1/012001.

Received: July 29, 2021; accepted: November 29, 2021 